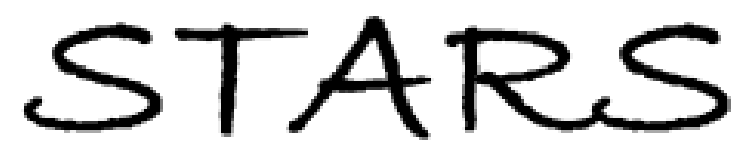

University of Central Florida

STARS

$1-1-2009$

\title{
Mechanically induced fcc phase formation in nanocrystalline hafnium
}

\author{
U. M. R. Seelam \\ University of Central Florida \\ C. Suryanarayana \\ University of Central Florida
}

Find similar works at: https://stars.library.ucf.edu/facultybib2000

University of Central Florida Libraries http://library.ucf.edu

This Article is brought to you for free and open access by the Faculty Bibliography at STARS. It has been accepted for inclusion in Faculty Bibliography 2000s by an authorized administrator of STARS. For more information, please contact STARS@ucf.edu.

\section{Recommended Citation}

Seelam, U. M. R. and Suryanarayana, C., "Mechanically induced fcc phase formation in nanocrystalline hafnium" (2009). Faculty Bibliography 2000s. 2112.

https://stars.library.ucf.edu/facultybib2000/2112

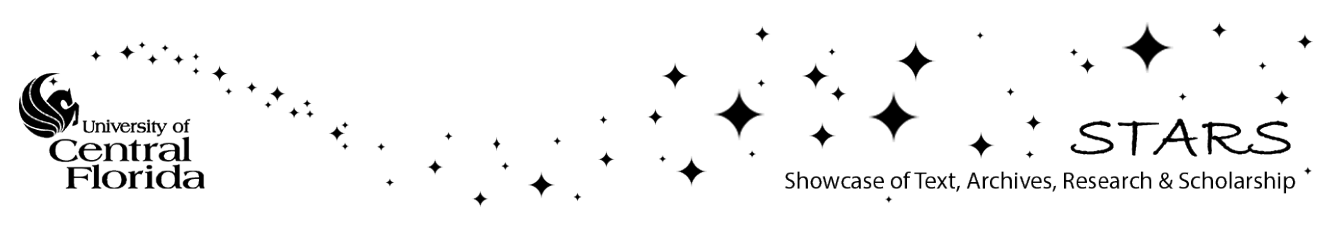




\section{Mechanically induced fcc phase formation in nanocrystalline hafnium}

Cite as: J. Appl. Phys. 105, 063524 (2009); https://doi.org/10.1063/1.3100037

Submitted: 17 November 2008 . Accepted: 16 February 2009 . Published Online: 25 March 2009

U. M. R. Seelam, and C. Suryanarayana

\section{ARTICLES YOU MAY BE INTERESTED IN}

Formation of face-centered-cubic zirconium by mechanical attrition

Applied Physics Letters 81, 4136 (2002); https://doi.org/10.1063/1.1519942

Formation of face-centered-cubic titanium by mechanical attrition

Journal of Applied Physics 93, 1520 (2003); https://doi.org/10.1063/1.1530718

High- $\kappa$ gate dielectrics: Current status and materials properties considerations

Journal of Applied Physics 89, 5243 (2001); https://doi.org/10.1063/1.1361065

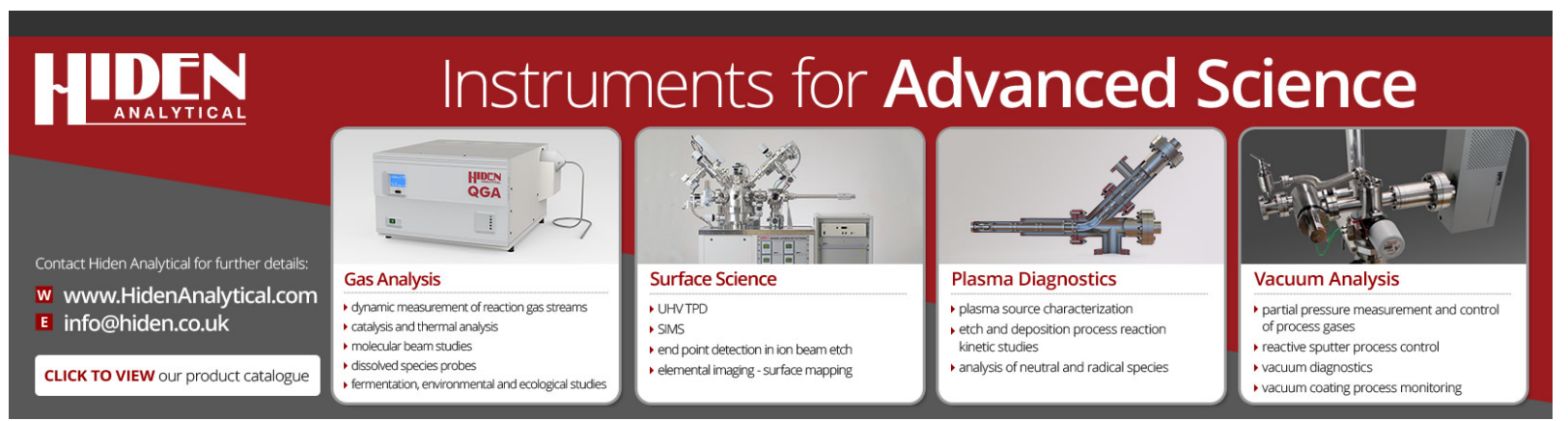




\title{
Mechanically induced fcc phase formation in nanocrystalline hafnium
}

\author{
U. M. R. Seelam and C. Suryanarayana ${ }^{a)}$ \\ Department of Mechanical, Materials and Aerospace Engineering, University of Central Florida, Orlando, \\ Florida 32816-2450, USA
}

(Received 17 November 2008; accepted 16 February 2009; published online 25 March 2009)

\begin{abstract}
A face-centered-cubic (fcc) phase was obtained in high-purity hafnium (Hf) metal powders subjected to mechanical milling in a high-energy SPEX shaker mill. X-ray diffraction and electron microscopy techniques were employed to evaluate the structural changes in the milled powder as a function of milling time. The effects of mechanical milling included a reduction in grain size, an increase in lattice strain, and formation of an fcc phase instead of an equilibrium hexagonal-close-packed (hcp) phase. During milling, the grain size of Hf decreased to below about $7 \mathrm{~nm}$. Additionally, there was approximately $6 \%$ increase in atomic volume during the formation of the fcc phase. Chemical analysis of the milled powder indicated the presence of significant amounts of interstitial impurities. Even though any or all of the above factors could contribute to the formation of the fcc phase in the milled powder, it appears that the high level of interstitial impurities is at least partially responsible for the formation of the fcc phase. (C) 2009 American Institute of Physics. [DOI: 10.1063/1.3100037]
\end{abstract}

\section{INTRODUCTION}

Nanocrystalline materials have been receiving the serious attention of researchers in recent years. This has been essentially due to the fact that in comparison to the coarsegrained materials, nanocrystalline materials possess different and often superior mechanical, electrical, and magnetic properties. ${ }^{1-5}$ In addition to the improvement in properties, there have also been several reports on constitutional changes and phase transformations in materials that have nanometered grain sizes. These transformations include allotropic transformations in pure metals, ${ }^{6-10}$ alloys, ${ }^{11}$ and compounds. ${ }^{12}$ It has also been reported that solid solubility limits could be significantly increased by nanostructure pressing. ${ }^{13,14}$ Thus, there appears to be great potential in altering the crystal structure and, consequently, the properties of nanocrystalline materials. In addition to these experimental observations, there have also been some theoretical studies which reported that allotropic transformations could be induced in pure metals when their grain sizes reach below some critical values. ${ }^{15}$ Crystal lattice distortion and interfacial effects were found to be the reasons for structural instability.

During a detailed investigation on the effects of mechanical alloying on the amorphization behavior and constitution of $\mathrm{Cu}-\mathrm{Hf}$ binary powder mixtures containing about 35 at. $\%$ Hf, we noted the formation of a face-centeredcubic (fcc) phase with a lattice parameter of $0.4566 \mathrm{~nm} .{ }^{16}$ Occurrence of such an fcc phase in the $\mathrm{Cu}-\mathrm{Hf}$ system could not be explained on the basis of formation of a supersaturated solid solution of $\mathrm{Hf}$ in $\mathrm{Cu}$ achieved by mechanical alloying methods. It was also not possible to explain this observation on the basis of a metastable intermetallic phase with the composition of either $\mathrm{Cu}_{2} \mathrm{Hf}$ or $\mathrm{Hf}_{2} \mathrm{Cu}$ having the $\mathrm{CaF}_{2}$-type crystal structure. Since it is possible that the equi-

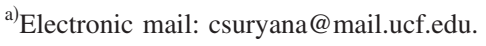

librium hexagonal-close-packed (hcp) form of Hf could undergo an allotropic transformation into the fcc form under the nonequilibrium conditions of mechanical alloying, it was decided to investigate whether this is a possibility in the pure metal Hf. Thus, we report here the hcp $\rightarrow$ fcc phase transformation in nanostructured elemental hafnium induced by mechanical milling (MM). Under equilibrium conditions, Hf exists in the hcp form with $a=0.3195 \mathrm{~nm}, c=0.5051 \mathrm{~nm}$, and $c / a=1.581$ up to $1743{ }^{\circ} \mathrm{C}$. Above this temperature, it transforms into the body-centered-cubic (bcc) form with $a$ $=0.3610 \mathrm{~nm}^{17}$

MM is a milling process that involves repeated cold welding, fracturing, and rewelding of powder particles in a high-energy ball mill. MM results in structural and microstructural modifications, including formation of metastable phases, phase transformations, and synthesis of materials with ultrafine grain sizes, down to nanometer dimensions. $^{18,19}$

\section{EXPERIMENTAL PROCEDURE}

Elemental hafnium ( $>99$ wt \% purity) of -325 mesh ( $\sim 45 \mathrm{~m}$ particle size) was milled in a high-energy SPEX 8000D Mixer mill. The milling was done in a stainless steel container using hardened stainless steel balls with a ball-topowder weight ratio of 10:1. About 1 wt \% of stearic acid was used as a process control agent to minimize/avoid cold welding of powder particles between themselves and the milling container. The loading, unloading, and general handling of the hafnium powder was carried out in an argonfilled glove box.

Structural evolution in the milled powder was studied using x-ray diffraction (XRD) employing $\mathrm{Cu} K \alpha$ radiation. The crystal structure and lattice parameters were determined using standard XRD methods. ${ }^{20}$ The average crystallite size, $t$, in the milled powders was determined from the width of the $\mathrm{x}$-ray peaks using the Scherrer equation, 


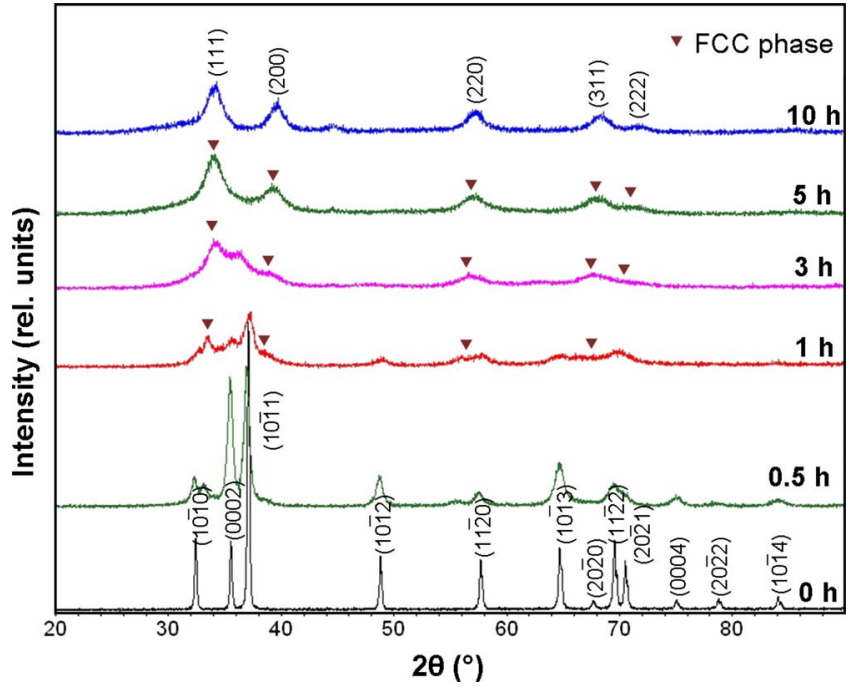

FIG. 1. (Color online) XRD patterns of the pure metal powder hafnium mechanically milled from 0.5 to $10 \mathrm{~h}$. While all the diffraction peaks characteristic of the hcp phase with the expected lattice parameters were present in the starting powder, a completely new fcc phase started appearing on milling the powder for as short as $0.5 \mathrm{~h}$. The $\mathrm{hcp} \rightarrow \mathrm{fcc}$ phase transformation was complete at $5 \mathrm{~h}$ of milling. No further changes were detected on continued milling up to $10 \mathrm{~h}$.

$$
t=\frac{0.9 \lambda}{B \cos \theta},
$$

where $\lambda$ is the wavelength of the $\mathrm{x}$ radiation used, $B$ is the full width at half maximum intensity, and $\theta$ is the Bragg angle. The lattice strain in the milled powder was also determined after subtracting the contributions due to instrumental effects and crystallite size to the width of the x-ray reflections.

\section{RESULTS}

Figure 1 shows the XRD patterns of $\mathrm{Hf}$ as a function of milling time. The as-received powder showed all the peaks expected from the hcp structure with the lattice parameters $a=0.3196 \mathrm{~nm}$ and $c=0.5054 \mathrm{~nm}$. On milling the powder, the diffraction peaks became broader due to grain refinement

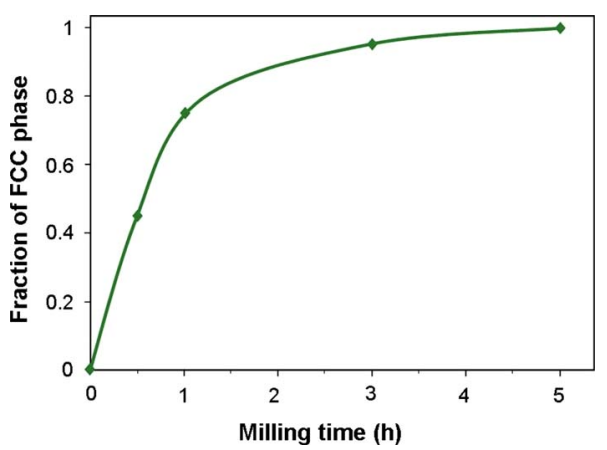

FIG. 2. (Color online) Variation in the fraction of the fcc phase formed in mechanically milled $\mathrm{Hf}$ powder as a function of milling time. While the transformation from the hcp into the fcc phase started on milling the powder for $0.5 \mathrm{~h}$, the transformation was complete in about $5 \mathrm{~h}$.

and introduction of lattice strain. But after milling for as short as $0.5 \mathrm{~h}$, some new diffraction peaks, although with low intensity, started appearing. The intensity of these new peaks continued to increase with milling time, and that of the hcp peaks decreased. Such a situation continued for $5 \mathrm{~h}$ when the peaks characteristic of the hcp phase were completely absent, and therefore, it could be concluded that the hcp phase has completely transformed into this new phase. All the peaks of this new phase could be most satisfactorily indexed on the basis of an fcc structure. Based on the appropriate extrapolation functions to obtain the precise lattice parameter, it was noted that the lattice parameter for this new fcc phase was $a=0.4566 \mathrm{~nm}$. No further structural changes in the powder occurred even after milling the powder for longer periods of time, say, $10 \mathrm{~h}$.

Figure 2 shows the fraction of the fcc phase formed in the milled Hf powder as a function of milling time. It was noted that the kinetics of formation of the fcc phase were quite fast in the early stages of milling, and then they decreased at a later stage. Complete transformation from the hcp into the fcc phase took place in about $5 \mathrm{~h}$.

Formation of the fcc phase was confirmed through electron diffraction methods also. Figure 3 shows the electron diffraction pattern from the powder milled for $5 \mathrm{~h}$. The pat-
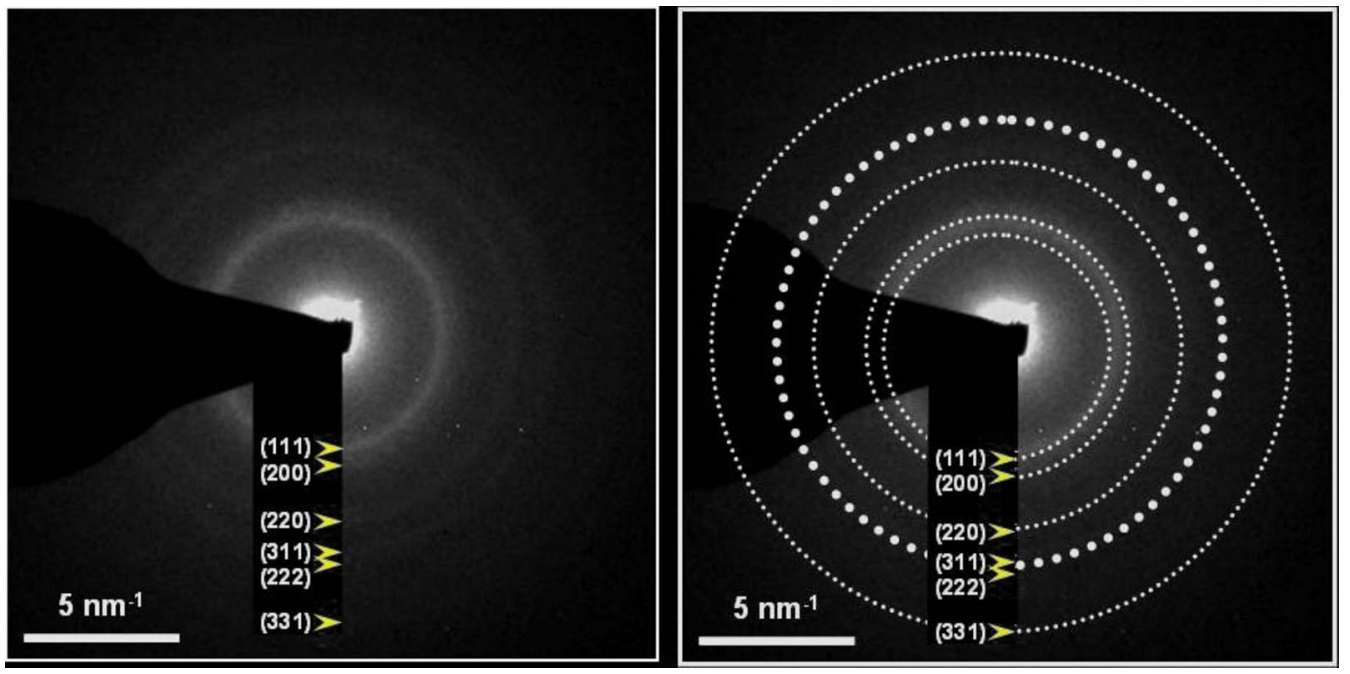

FIG. 3. (Color online) Electron diffraction pattern of the Hf powder milled for $5 \mathrm{~h}$, confirming the presence of only an fcc phase at this stage. 


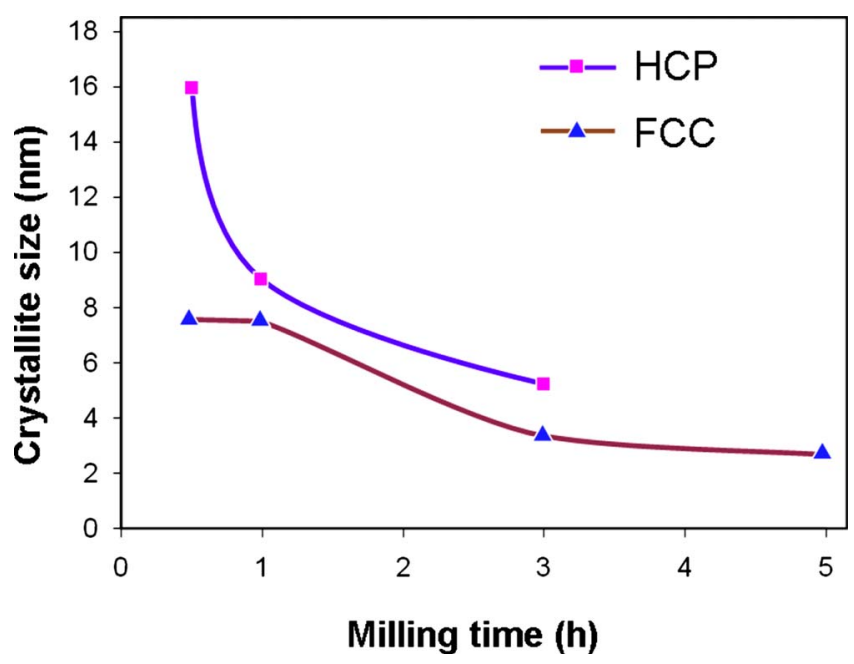

FIG. 4. (Color online) Variation in the crystallite size in both the hcp and fcc phases of hafnium as a function of milling time. The crystallite size decreased rapidly in the early stages of milling and reached a minimum value of about $3 \mathrm{~nm}$ in the fcc phase.

tern was indexed on the basis of an fcc structure with the lattice parameter $a=0.45 \mathrm{~nm}$, and this value is very close to the result obtained from the XRD patterns.

The crystallite (grain) size of both parent hcp and product fcc phases was measured at different milling times, and the results are shown in Fig. 4. The crystallite size variation is typical of mechanically milled powders. The grain size decreased initially at a very fast rate and reached about 10 $\mathrm{nm}$ on milling the powder for $1 \mathrm{~h}$. From then onward, the rate of decrease in crystallite size was slow. The minimum crystallite size achieved in the hcp phase was $5 \mathrm{~nm}$. The crystallite size of the fcc phase at the start of its formation was approximately $7 \mathrm{~nm}$ and decreased slowly to a value of $3 \mathrm{~nm}$ at $5 \mathrm{~h}$, suggesting that the formation of this phase could probably be associated with grain size reduction into the nanometer range.

The variation in lattice strain in the milled powder in both the hcp and fcc forms of Hf was estimated from the peak widths, and the values are plotted in Fig. 5. The lattice strain increased in both the cases with milling time. While the strain was compressive in nature when the powder was in the fcc form, it was tensile in the hcp form.

\section{DISCUSSION}

From the above results, it becomes clear that an fcc phase had formed on mechanically milling the Hf metal

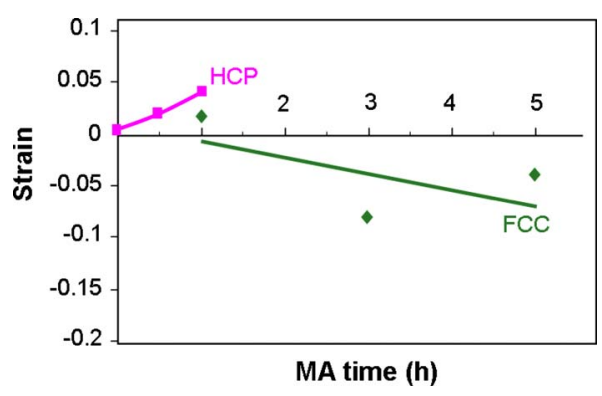

FIG. 5. (Color online) Variation in lattice strain in the mechanically milled $\mathrm{Hf}$ powder as a function of milling time. Note that the strain increases with increasing milling time (up to the time investigated) and that the strain is compressive in nature in the fcc form of Hf. powder for $5 \mathrm{~h}$. Since there is no stable equilibrium phase of Hf with the fcc structure, it can be assumed that this is a metastable form of Hf formed under the nonequilibrium conditions of MM. Therefore, it becomes important for us to investigate the reasons for its formation.

Assuming that the Hf metal has undergone an allotropic transformation, we can calculate the lattice parameter of the hypothetical fcc phase of Hf on the basis of the lattice parameters of the equilibrium hcp structure and using the relationship

$$
a_{\mathrm{fcc}}=\sqrt{ } 2 \times a_{\mathrm{hcp}}=\sqrt{ } 2 \times 0.3195 \mathrm{~nm}=0.4517 \mathrm{~nm} .
$$

Assuming an ideal axial ratio of 1.633 for the hcp structure of Hf, even though this is not actually true, and it is 1.581, the lattice parameter of the fcc phase can also be calculated using the relationship

$$
\begin{aligned}
a_{\mathrm{fcc}} & =\sqrt{ } 2 \times\left(c_{\mathrm{hcp}} / 1.633\right)=\sqrt{ } 2 \times(0.5051 \mathrm{~nm} / 1.633) \\
& =0.4374 \mathrm{~nm} .
\end{aligned}
$$

Alternatively, assuming that the closest distance of approach between two atoms, $2 r$, in a hcp structure with a nonideal axial ratio is given by

$$
2 r=\sqrt{\frac{a^{2}}{3}+\frac{c^{2}}{4}},
$$

the lattice parameter of the hypothetical fcc phase formed from such a hcp structure is calculated to be $0.4422 \mathrm{~nm}$.

It has also been suggested ${ }^{21}$ that the closest distance of approach between atoms in the hcp structure is along the $\langle 20 \overline{2} 3\rangle$ directions and is given by

$$
2 r=\frac{a\left[4+3\left(\frac{c}{a}\right)^{2}\right]^{1 / 2}}{2 \sqrt{3}} .
$$

According to this equation, the closest distance of approach in the hcp structure of $\mathrm{Hf}$ is calculated to be $0.3128 \mathrm{~nm}$, and therefore, the lattice parameter of the hypothetical fcc phase is $0.4422 \mathrm{~nm}$.

Thus, the lattice parameters of the fcc phase calculated by any of the above four methods are somewhat close to each other, differing only by about $3 \%$. The lattice parameter of the fcc phase formed in the Hf powder in the present investigation $(0.4566 \mathrm{~nm})$ is slightly larger than any of these values. We will see later that this increase is related to the nanostructured grains formed, and possibly to contamination, in the milled powder.

Allotropic phase transformations in pure metals can occur due to changes in temperature, pressure, or alloying additions. Additionally, changes in microstructural parameters such as grain size, surface energy, and stacking-fault energy can have a significant influence in affecting these transformations. Stabilization of some phases due to the presence of impurities, especially during mechanical alloying/milling of powders, is also well known. ${ }^{18,19,22}$ Let us now look at the different possibilities to explain the occurrence of the hcp $\rightarrow$ fcc transformation in elemental Hf. 


\section{A. Effect of temperature}

As mentioned earlier, Hf exists in the hcp form at room temperature and transforms into the bcc form, which is stable at temperatures $>1743{ }^{\circ} \mathrm{C}$. The process of MM takes place at or near room temperature. But due to the high-energy milling conditions, a slight rise in powder temperature is reported to occur. There have been different estimates of the local temperature rise, but it is now accepted that it is not more than about $200{ }^{\circ} \mathrm{C} .{ }^{18,19,23}$ Thus, this temperature rise obtained during milling is not sufficient enough to cause any crystal structure change in the Hf powder. Further, irrespective of whether the temperature rise is responsible for this transformation or not, there is no reported stable phase of $\mathrm{Hf}$ with the fcc structure at high temperatures. Therefore, formation of an fcc phase in Hf due to changes in temperature can be completely ruled out.

\section{B. Effect of pressure}

Allotropic phase transformations in pure metals due to application of high pressures have been known for a long time. $^{24}$ New metastable phases have also been reported to form at relatively high pressures. ${ }^{25}$ It has been estimated that very high pressures of the order of 6-8 GPa could be developed during mechanical alloying/milling due to the impact forces exerted by the grinding medium on the powders. ${ }^{26} \mathrm{But}$ there have not been any reports of formation of an fcc phase in Hf under high pressures so far. Thus, even though it is possible that this fcc phase could be a high-pressure polymorph of Hf, this fact can only be confirmed if an fcc form of Hf is obtained by subjecting the pure metal Hf to regular high pressures and not inside the SPEX milling container.

\section{Effect of stacking-fault energy}

Metals with low stacking-fault energy, e.g., Co, are expected to easily undergo allotropic transformations through a twinning mechanism, similar to a martensitic transformation. ${ }^{27}$ This has been reported in mechanically milled metal powders also. ${ }^{6}$ Thus, a possibility for the hcp $\rightarrow$ fcc allotropic transformation in Hf in the present study is a twinning process. Formation of twins occurs easily in materials with a low stacking-fault energy. ${ }^{28}$ But Igarashi et al. ${ }^{29}$ estimated the stacking-fault energy of $\mathrm{Hf}$ to be about $111 \mathrm{~mJ} / \mathrm{m}^{2}$. This value is neither very low $\left(20-40 \mathrm{~mJ} / \mathrm{m}^{2}\right)$ like that in Co or austenitic stainless steel nor very high $\left(200 \mathrm{~mJ} / \mathrm{m}^{2}\right)$ like that in Al. However, formation of twins has been reported to occur in the so-called high stackingfault energy metals also when they exist in the nanocrystalline state. Accordingly, twins were reported to form in cryomilled nanocrystalline $\mathrm{Al},{ }^{30,31}$ as predicted by molecular dynamics simulation studies. ${ }^{32}$ It has been suggested that the stacking-fault energy of a metal decreases with a decrease in the grain size to nanometer dimensions and helps in the formation of twins. A rationale was recently provided for the strong dependence of mechanical twinning on grain size. ${ }^{33}$ Since the grain size obtained in the present investigation is in the nanometer range, it is possible that low stacking-fault energy (and consequently twinning) could be the reason for the formation of the fcc phase in Hf.
Zheng et al. ${ }^{34}$ recently reported, through molecular dynamics simulations, that the $\mathrm{hcp} \rightarrow \mathrm{fcc}$ transformation in nanocrystalline cobalt during tension and compression was due to the accumulation of deformation faults.

\section{Effect of nanocrystallinity}

From Fig. 4 it is clear that the fcc-Hf phase produced in this investigation is nanocrystalline in nature with a typical crystallite (grain) size of a few nanometers. Since nanocrystalline materials are characterized by small grain sizes and a large volume fraction of atoms residing at the grain boundaries (and therefore large surface areas), the thermodynamic stabilities of the different phases could be significantly altered. $^{1-5}$ Consequently, it has been possible to synthesize metastable phases that are different from those present in their coarse-grained counterparts. Further, a significant amount of strain is also stored in the lattice of the milled powder (Fig. 5). Therefore, it is worthwhile to consider the effects of nanocrystallinity on the thermodynamic stabilities of the competing phases in Hf under the conditions of MM.

The different factors that contribute to the free energy of the nanocrystalline system are the surface energy, excess free volume, and lattice strain. The contribution to the increase in the free energy in a nanocrystalline material has to be considered in terms of the decreased grain size and associated increase in the grain boundary component.

A reduction in grain size $(L)$ leads to an increase in the free energy $\Delta G$ of the system due to the Gibbs-Thompson effect according to the equation ${ }^{35}$

$$
\Delta G=\frac{4 \gamma N_{A} V_{a}}{L},
$$

where $\gamma$ is the interfacial energy, $N_{A}$ is the Avogadro's number, and $V_{a}$ is the atomic volume. The atomic volumes of Hf in the hcp and fcc forms were calculated, from the respective lattice parameter values, as $V_{\mathrm{hcp}}=0.0223 \mathrm{~nm}^{3}$ and $V_{\mathrm{fcc}}$ $=0.0236 \mathrm{~nm}^{3}$, suggesting that the $\mathrm{hcp} \rightarrow$ fcc transformation is associated with an approximately $6 \%$ volume increase. Such lattice expansions on phase transformations and/or on decreasing the grain size were reported earlier in $\mathrm{Nb},{ }^{36} \mathrm{Ni},{ }^{37}$ $\mathrm{Ti}^{9}{ }^{9}$ and $\mathrm{Zr},{ }^{8}$ among others. This increase in $V_{a}$ is expected to result in an increase in the free energy of the system.

On the other hand, it has been shown earlier ${ }^{38}$ that atoms in the grain boundaries of nanocrystalline materials are randomly displaced from their regular atomic sites, and therefore they contain a certain amount of excess free volume. The excess free volume $\Delta V_{F}$ associated with the atoms in the grain boundaries can be calculated using the equation

$$
\Delta V_{F}=\frac{(L+\Delta / 2)^{2}-L^{2}}{L^{2}},
$$

where $L$ is the grain size and $\Delta$ is the grain boundary width. Even though $\Delta$ has been traditionally assumed to be $1 \mathrm{~nm}$ and independent of grain size, ${ }^{39}$ it has been shown recently ${ }^{36}$ that the value of $\Delta$ changes with the grain size of the nanocrystalline material and that it increases with a decrease in the grain size. This excess free volume generates a negative hydrostatic pressure (from core to periphery) and could result 
TABLE I. Structural parameters of pure Hf and the interstitial phases with an fcc structure in the Hf-C and $\mathrm{Hf}-\mathrm{N}$ systems.

\begin{tabular}{|c|c|c|c|c|c|c|}
\hline \multirow[b]{2}{*}{ Phase } & \multirow{2}{*}{$\begin{array}{l}\text { Crystal structure } \\
\text { (prototype, } \\
\text { Strukturbericht } \\
\text { designation) }\end{array}$} & \multirow[b]{2}{*}{$\begin{array}{l}\text { Pearson } \\
\text { symbol }\end{array}$} & \multirow[b]{2}{*}{$\begin{array}{l}\text { Space } \\
\text { group }\end{array}$} & \multirow{2}{*}{$\begin{array}{c}\text { Composition range } \\
\text { of stability } \\
\text { (at. \%) }\end{array}$} & \multicolumn{2}{|c|}{ Lattice parameters } \\
\hline & & & & & $\begin{array}{c}a \\
(\mathrm{~nm})\end{array}$ & $\begin{array}{c}c \\
(\mathrm{~nm})\end{array}$ \\
\hline$\alpha$-Hf & $\begin{array}{c}\text { hcp } \\
(\mathrm{Mg}, \mathrm{A} 3 \text {-type }) \\
\text { bcc }\end{array}$ & $\mathrm{hP} 2$ & $P 6_{3} / m m c$ & $100 \% \mathrm{Hf}$ & 0.3195 & 0.5051 \\
\hline$\beta$-Hf & $\begin{array}{c}\text { (W, A2-type) } \\
\text { fcc }\end{array}$ & $\mathrm{cI} 2$ & $\operatorname{Im} \overline{3} m$ & $100 \% \mathrm{Hf}$ & 0.3610 & $\cdots$ \\
\hline $\mathrm{HfC}$ & $\begin{array}{c}\text { (NaCl, B1-type }) \\
\text { fcc }\end{array}$ & $\mathrm{cF} 8$ & $F m \overline{3} m$ & $37.5-49.5$ at. $\% \mathrm{C}$ & 0.4633 & $\cdots$ \\
\hline $\mathrm{HfN}$ & (NaCl, B1-type) & $\mathrm{cF} 8$ & $F m \overline{3} m$ & $46-52.5$ at. $\% \mathrm{~N}$ & 0.4525 & $\cdots$ \\
\hline
\end{tabular}

${ }^{\mathrm{a} \text { At room temperature. }}$

in crystal lattice expansion. At a grain size of $d=7.5 \mathrm{~nm}$, the value of $\Delta V_{F}$ has been calculated to be 0.14 .

Rose et al. $^{40}$ used a lattice dilatation model known as the isothermal equation of state, which was subsequently adopted by Fecht ${ }^{41}$ to calculate the hydrostatic pressure at the grain boundaries in nanocrystalline materials. The hydrostatic pressure $P_{h}$ was calculated using the equation

$$
\begin{aligned}
P_{h}= & -\frac{3 B_{o}\left[\left(V / V_{o}\right)^{1 / 3}-1\right]}{\left(V / V_{o}\right)^{2 / 3}} \exp \left(-a^{*}\right) \times\left[1-0.15 a^{*}\right. \\
& \left.+0.05\left(a^{*}\right)^{2}\right]
\end{aligned}
$$

where $B_{o}$ is the equilibrium bulk modulus, $V_{o}$ is the volume per atom of the equilibrium coarse-grained material, $V$ is the volume per atom in the nanocrystalline state, and $a^{*}$ is the scaling parameter defined as $\left(r_{\mathrm{WS}}-r_{\mathrm{WS} e}\right) / L$, where $r_{\mathrm{WS}}$ is the real Wigner-Seitz cell radius of the atom with a volume $V$, $r_{\mathrm{WS} e}$ is the Wigner-Seitz cell radius of the atom with a volume $V_{o}$, and $L$ is the length scale (grain size) characteristic of the metal. It is to be noted that $\Delta V_{F}$ in Eq. (7) is related to Eq. (8) through the relationship

$$
\Delta V_{F}=\frac{V-V_{o}}{V_{o}} .
$$

Using the appropriate values for the different parameters, $P_{h}$ has been calculated to be $-10.5 \mathrm{GPa}$ for a grain size of 7.5 $\mathrm{nm}$ in Hf.

The product of the negative hydrostatic pressure and atomic volume change (difference in the atomic volumes of the hcp and fcc forms of Hf), i.e., $P_{h} \times \Delta V_{a}$, is an energy term, and these values can be calculated as a function of grain size. It is noted that the energy increases with a decrease in grain size. For the grain size of $7.5 \mathrm{~nm}$ observed in the present study, the $P_{h} \times \Delta V_{a}$ value has been calculated to be $3450 \mathrm{cal} / \mathrm{mol}$. Kaufman ${ }^{42}$ has theoretically estimated the free energy change necessary for the transformation of metals from the hcp into the fcc structure as $800 \mathrm{cal} / \mathrm{mol}$. This amount of energy can be obtained when the grain size of the Hf metal is reduced to about $18.7 \mathrm{~nm}$. That is, below a grain size of $18.7 \mathrm{~nm}$, the Hf metal has sufficiently high energy to transform from the hcp into the fcc structure. Since the grain size obtained in the milled Hf powder (with the fcc structure) was $7.5 \mathrm{~nm}$ (and therefore the energy available is large), it can be argued that the excess energy present, as a result of reduction in grain size, could have stabilized the fcc phase in Hf.

The increase in energy due to the combination of the above effects may eventually cause a high order of lattice instability, and consequently the hcp phase of Hf could adopt a new polymorph with greater topological or surface density of atoms, but without altering the crystal packing density $(=74 \%) .8,9,11$ Thus, the hcp $\rightarrow$ fcc transformation observed in elemental Hf in this investigation can be considered an allotropic transformation.

It has been frequently highlighted in the literature on crystal chemistry that metals in the same group of the periodic table have the same (or similar) crystal structures. Thus, under equilibrium conditions, the group IV transition metals $\mathrm{Ti}, \mathrm{Zr}$, and Hf have the hcp crystal structure at room temperature and transform into the bcc structure at elevated temperatures. Formation of metastable fcc allotropes has been reported to occur in mechanically milled $\mathrm{Ti}$ (Ref. 9) and $\mathrm{Zr}$ (Ref. 8) powders. Therefore, it can be expected that a similar metastable fcc phase would form in mechanically milled Hf powder, and the result obtained in the present investigation fulfills this expectation.

\section{E. Presence of impurities}

This is yet another possibility for a phase transformation to occur in pure metals. Since we are dealing with only a pure metal in this investigation, the presence of alloying elements as responsible for the formation of an fcc phase can be ruled out. But the technique of mechanical alloying/ milling is known to introduce impurities (both substitutional and interstitial) into the milled powder, and this has been recognized as a serious limitation of the technique in developing novel materials for advanced applications. The impurities could be either metallic in nature from the milling medium and/or the milling container or gaseous from the ambient atmosphere in which the milling is done or the process control agent added occasionally to minimize excessive cold welding between ductile metal particles. ${ }^{19}$

Interstitial phases with an fcc structure are present in the $\mathrm{Hf}-\mathrm{C}$ and Hf-N systems. Table I lists the crystal structures and lattice parameters of these phases. The lattice parameter 


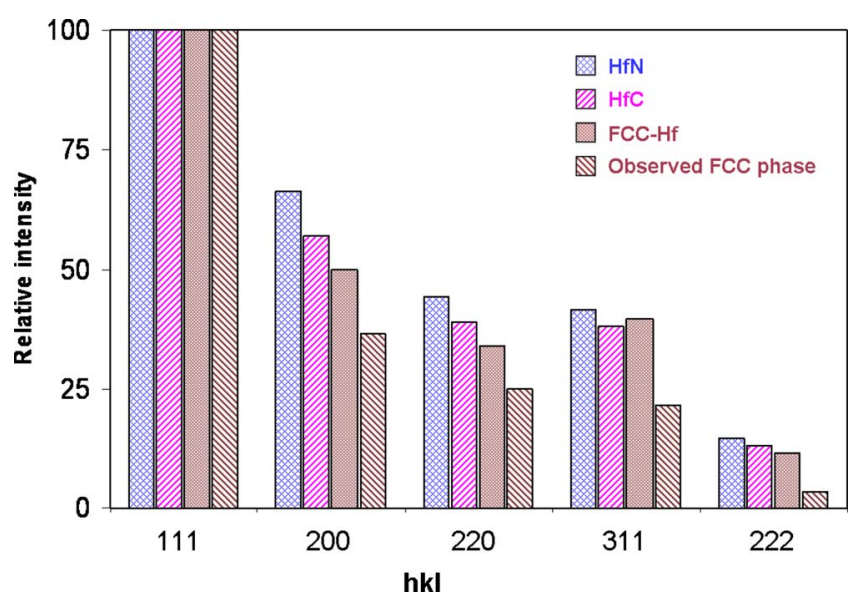

FIG. 6. (Color online) Comparison of the relative intensities of the first five diffraction peaks of the fcc structure $(111,200,220,311$, and 222) for four different cases-experimentally observed fcc phase, hypothetical fcc phase of $\mathrm{Hf}, \mathrm{NaCl}$ (B1)-type $\mathrm{HfC}$, and $\mathrm{NaCl}$ (B1)-type HfN. Note that the observed intensities seem to match better with the hypothetical fcc phase.

of the fcc phase synthesized by MM of Hf powders was calculated as $a=0.4566 \mathrm{~nm}$. Comparison with the values in Table I clearly suggests that the fcc phase obtained in this investigation has a lattice parameter smaller than that of $\mathrm{HfC}$ $(a=0.4633 \mathrm{~nm})$ but larger than that of $\operatorname{HfN}(a$ $=0.4525 \mathrm{~nm})$. Thus, we need to decide whether it is possible for the new fcc phase formed in the milled Hf powder to be either HfC or HfN.

Further, assuming that the HfN phase may also exist in a metastable condition with the $\mathrm{ZnS}$, B3-type (cubic) structure, the lattice parameter for this hypothetical phase was calculated to be $0.4883 \mathrm{~nm}$. Since this value is substantially larger than the experimentally observed value, the possibility that the observed fcc phase in the present investigation could be the ZnS-type cubic HfN has been discounted.

Apart from a match of the diffraction angles, the relative intensities of the different diffraction peaks in the structure also need to match to ensure that the structure assigned to it is correct. Accordingly, the relative intensities, $I_{\text {rel }}$ of the first five allowed reflections in the fcc structure; viz., 111, 200, 220, 311, and 222 have been calculated using the equation

$$
I_{\mathrm{rel}}=\left|F_{h k l}\right|^{2} p\left(\frac{1+\cos ^{2} 2 \theta}{\sin ^{2} \theta \cos \theta}\right),
$$

where $F_{h k l}$ is the structure factor for the $h k l$ reflection, $p$ is the multiplicity factor, $\left(\left(1+\cos ^{2} 2 \theta\right) /\left(\sin ^{2} \theta \cos \theta\right)\right)$ is the Lorentz-polarization factor, and $\theta$ is the Bragg angle. The intensity values were calculated for three different crystal structures, viz., B1-type HfC, B1-type HfN, and hypothetical fcc form of Hf. Figure 6 compares these calculated intensities with the intensities observed for the fcc phase in the present investigation.

A few general observations may be noted from this figure. First, it is clear that the trend of variation in the intensities for the different diffraction peaks is the same for all the four structures-observed fcc phase, hypothetical fcc Hf, $\mathrm{NaCl}$ (B1)-type $\mathrm{HfC}$, and $\mathrm{NaCl}$ (B1)-type HfN phases. Second, it may be noted that the intensities of the hypothetical fcc-Hf phase and the observed fcc phase are somewhat lower than those of the HfC and HfN phases for the 200, 220, 311, and 222 reflections (except for a small reversal between fcc-Hf and HfC phases for the 311 reflection). In fact, the intensities of the observed fcc phase are significantly lower than those calculated for the HfC and HfN phases but much closer to those of the hypothetical fcc-Hf phase. Therefore, from these intensity calculations, it is very unlikely that the observed fcc phase in the present investigation is either the B1-type HfN or HfC phase. It is more likely that it is the hypothetical (metastable) fcc phase of Hf.

In addition to the diffraction angles and relative intensities of the different diffraction peaks, it is also important to ensure that the chemical composition of the new phase matches with that of the identified phase. According to the binary $\mathrm{Hf}-\mathrm{N}$ and $\mathrm{Hf}-\mathrm{C}$ phase diagrams, the HfN phase exists over a composition range of $46-52.5$ at. $\% \mathrm{~N}$, and the $\mathrm{HfC}$ phase in the composition range of $37.5-49.5$ at. \% $\mathrm{C}$, at room temperature. This means that for the homogeneous $\mathrm{HfN}$ and HfC phases to form in the milled powder, one needs a minimum of 46 at. $\% \mathrm{~N}$ and 37.5 at. \% C, respectively.

Conventional wet chemical analysis of the Hf powder milled for $5 \mathrm{~h}$ showed that the nitrogen content in the powder was a maximum of 14 and 12 at. \% on milling for 5 and 10 $\mathrm{h}$, respectively, in the worst possible milling condition. (Since the chemical analysis was done some time after the powders were milled, it is possible that the powders picked up additional nitrogen during storage.) Even though these values are slightly high (the nitrogen contamination was much less when proper precautions were taken), they are not high enough to form the HfN phase. According to the Hf-N binary phase diagram, the solid solubility of nitrogen in hafnium at room temperature is 29 at. \%, and therefore, only an interstitial solid solution of nitrogen in hcp-Hf is expected to form up to this nitrogen level. But we did not detect the presence of any hcp phase along with the fcc phase in the powder milled for $5 \mathrm{~h}$ or longer. This observation suggests that with the amount of nitrogen present, it is not possible to produce even a small amount of the HfN phase in the milled powder and that the fcc phase observed in the milled powder cannot be the HfN phase. A Hf(N) solid solution phase with a hcp structure is also not present in the milled powder.

Similarly, the carbon content in the Hf powder was 10 at. $\%$ on milling for $5 \mathrm{~h}$ and 9 at. $\%$ in the powder milled for $10 \mathrm{~h}$. These values are again not high enough for any $\mathrm{HfC}$ to form in the powder. Accordingly, it is fair to assume that the new fcc phase formed in the milled Hf powder is neither HfN nor HfC.

Significant levels of impurities were also earlier reported in mechanically milled titanium ${ }^{9}$ and other metals, and these authors also had discounted the possibility of the new fcc phases being interstitial compounds containing nitrogen, carbon, or oxygen. In view of these observations, it will be difficult to interpret the formation of the fcc phase in the milled Hf powder purely as a contaminant phase.

From the above discussion, it appears that it will be difficult to decide the origin of the fcc phase in the milled Hf powder. Three possibilities stand out-one is the allotropic transformation, the second is the nanocrystalline nature of the powder, and the last is powder contamination. It cannot 


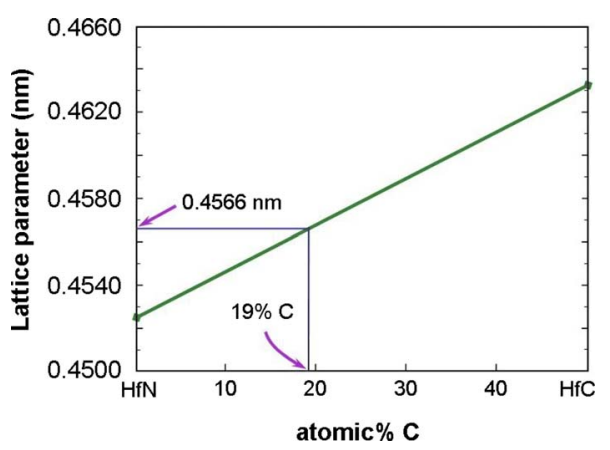

FIG. 7. (Color online) Variation in the lattice parameter of the $\mathrm{Hf}(\mathrm{N}, \mathrm{C})$ phase as a function of carbon content. From this plot, the lattice parameter of $0.4566 \mathrm{~nm}$ observed for the fcc phase in the present investigation corresponds to a carbon content of 19 at. \% and a nitrogen content of 31 at. \%, or in the ratio of approximately $2: 3$.

be determined unambiguously that an allotropic transformation occurs in the pure metal Hf since the powder contained significant amount of nitrogen and carbon as impurities. But the powder contamination by either nitrogen or carbon alone is not sufficiently high to homogeneously form either $\mathrm{HfN}$ or HfC. However, if we consider that the fcc phase formed in the milled powder is a solid solution of these two phases, i.e., hafnium carbonitride $[\mathrm{Hf}(\mathrm{N}, \mathrm{C})]$ with unequal proportions of carbon and nitrogen, it may be possible to resolve the confusion to some extent.

Assuming that the $\mathrm{HfN}$ and $\mathrm{HfC}$ phases form an isomorphous system and that the system obeys Vegard's law (linear variation of lattice parameter with solute content), Fig. 7 plots the variation in the lattice parameter of the $\mathrm{Hf}(\mathrm{N}, \mathrm{C})$ phase as a function of carbon content. If we assume that the fcc phase formed in the present investigation is a contaminant $\mathrm{Hf}(\mathrm{N}, \mathrm{C})$ phase, the calculated lattice parameter of $0.4566 \mathrm{~nm}$ for the fcc phase corresponds to a carbon content of 19 at. \% and a nitrogen content of 31 at. \%, or in the ratio of $0.38-0.62$ (and the rest Hf). Thus, it can be estimated that the fcc phase has a stoichiometry of $\operatorname{Hf}\left(\mathrm{C}_{0.4} \mathrm{~N}_{0.6}\right)$. But the measured carbon and nitrogen contents in the milled powder are only about 10 at. \% carbon and 14 at. \% nitrogen, or approximately half the required concentrations. From these observations, it can be assumed that the milled powder certainly contains the contaminant phase, but only to the extent of about $50 \%$. Since the carbon and nitrogen contents are not sufficiently high to form the $\operatorname{Hf}\left(\mathrm{C}_{0.4} \mathrm{~N}_{0.6}\right)$ phase homogeneously, it is likely that the milled powder contains about $50 \%$ of the $\operatorname{Hf}\left(\mathrm{C}_{0.4} \mathrm{~N}_{0.6}\right)$ phase and the rest another phase. But it should be noted that the observed XRD pattern contains only one phase with the fcc structure and $a$ $=0.4566 \mathrm{~nm}$. Therefore, it can be inferred that in addition to the $\operatorname{Hf}\left(\mathrm{C}_{0.4} \mathrm{~N}_{0.6}\right)$ phase, the milled powder contains another phase with the same structure and lattice parameter. It is very likely that this additional phase is the fcc allotrope of $\mathrm{Hf}$ formed under the nonequilibrium conditions of MM. But since the lattice parameter calculated for the fcc allotrope of $\mathrm{Hf}$ is smaller than the observed value, the observed larger value could be due to the nanocrystallinity of the powder. Thus, it appears that the fcc phase in the milled Hf powder in the present investigation can be considered to be a mixture of the product of an allotropic transformation and a contami- nant phase. At present it is not clear whether the fcc allotrope has formed first, and subsequently the contaminant phase has formed due to contamination of the powder, or the contaminant fcc phase has triggered the allotropic transformation. Additional and detailed investigations are required to unambiguously determine whether a true allotropic transformation occurs in Hf.

\section{CONCLUSIONS}

A phase transformation from the equilibrium hcp structure into the fcc structure occurred on milling pure Hf metal powder in a high-energy SPEX shaker mill. It was noted that during milling of the $\mathrm{Hf}$ powder, the grain (crystallite) size decreased to the nanometer level, and there was also significant lattice strain in the milled powder. The formation of the fcc phase was also accompanied by lattice expansion, leading to an increase in volume per atom by about $6 \%$. Based on the different possibilities for the formation of the fcc phase in Hf, viz., effects of temperature, pressure, nanocrystallinity, allotropic transformation, and impurities, etc., it was difficult to pinpoint the exact reason for the formation of the fcc phase. From the available evidence, it appears that the final powder may contain about $50 \%$ of the fcc phase as a result of the allotropic transformation, and the rest, a contaminant $\mathrm{Hf}\left(\mathrm{C}_{0.4} \mathrm{~N}_{0.6}\right)$ phase. This conclusion was reached because the amount of interstitial impurities (10 at. \% carbon and 14 at. \% nitrogen) was not sufficiently high to form the $\mathrm{Hf}\left(\mathrm{C}_{0.4} \mathrm{~N}_{0.6}\right)$ phase homogeneously.

\section{ACKNOWLEDGMENTS}

The authors wish to thank Dr. Eugene Ivanov of Tosoh SMD, Grove City, $\mathrm{OH}$ for the chemical analysis of the milled Hf powders.

${ }^{1}$ H. Gleiter, Prog. Mater. Sci. 33, 223 (1989).

${ }^{2}$ C. Suryanarayana, Int. Mater. Rev. 40, 41 (1995).

${ }^{3}$ H. Gleiter, Acta Mater. 48, 1 (2000).

${ }^{4}$ C. Suryanarayana, Adv. Eng. Mater. 7, 983 (2005).

${ }^{5}$ Nanostructured Materials, edited by C. C. Koch (William Andrew, Norwich, NY, 2007).

${ }^{6}$ J. Y. Haung, Y. K. Wu, and H. Q. Ye, Acta Mater. 44, 1201 (1996).

${ }^{7}$ L. Del Bianco, C. Ballesteros, J. M. Rojo, and A. Hernando, Phys. Rev. Lett. 81, 4500 (1998).

${ }^{8}$ I. Manna, P. P. Chattopadhyay, F. Banhart, and H.-J. Fecht, Appl. Phys. Lett. 81, 4136 (2002).

${ }^{9}$ I. Manna, P. P. Chattopadhyay, P. Nandi, F. Banhart, and H.-J. Fecht, J. Appl. Phys. 93, 1520 (2003).

${ }^{10}$ P. P. Chattopadhyay, S. K. Pabi, and I. Manna, Mater. Sci. Eng., A 304306, 424 (2001).

${ }^{11}$ S. Bera and I. Manna, J. Alloys Compd. 417, 104 (2006).

${ }^{12}$ Z. Li, H. Hahn, and R. W. Siegel, Mater. Lett. 6, 342 (1988)

${ }^{13}$ C. Suryanarayana and F. H. Froes, J. Mater. Res. 5, 1880 (1990).

${ }^{14}$ Y. Ogino, S. Murayama, and T. Yamasaki, J. Less-Common Met. 168, 221 (1991).

${ }^{15}$ W. Qin, T. Nagase, and Y. Umakoshi, J. Appl. Phys. 102, 124303 (2007).

${ }^{16}$ U. M. R. Seelam and C. Suryanarayana, (unpublished).

${ }^{17}$ T. B. Massalski, Binary Alloy Phase Diagrams (ASM International, Materials Park, OH, 1990).

${ }^{18}$ C. Suryanarayana, Prog. Mater. Sci. 46, 1 (2001).

${ }^{19} \mathrm{C}$. Suryanarayana, Mechanical Alloying and Milling (Marcel Dekker, New York, 2004).

${ }^{20}$ C. Suryanarayana and M. G. Norton, X-Ray Diffraction: A Practical Approach (Plenum, New York, 1998).

${ }^{21} \mathrm{~J}$. W. Christian, The Theory of Transformations in Metals and Alloys (Per- 
gamon, Oxford, 2002), Pt. I, p. 121

${ }^{22}$ C. Suryanarayana, Intermetallics 3, 153 (1995).

${ }^{23}$ C. C. Koch, Internat. J. Mechanochem. Mech. Alloying 1, 56 (1994).

${ }^{24}$ C. S. Barrett and T. B. Massalski, Structure of Metals, 3rd ed. (McGrawHill, New York, 1966).

${ }^{25}$ J. C. Jamieson and A. W. Lawson, J. Appl. Phys. 33, 776 (1962).

${ }^{26}$ D. R. Maurice and T. H. Courtney, Metall. Trans. A 21A, 289 (1990).

${ }^{27}$ P. Tolédano, G. Krexner, M. Prem, H.-P. Weber, and V. P. Dmitriev, Phys Rev. B 64, 144104 (2001)

${ }^{28}$ R. Abbaschian, L. Abbaschian, and R. E. Reed-Hill, Physical Metallurgy Principles, 4th ed. (Cengage Learning, Stamford, CT, 2009).

${ }^{29}$ M. Igarashi, M. Khantha, and V. Vitek, Philos. Mag. A 63, 603 (1991)

${ }^{30}$ X. Z. Liao, F. Zhou, E. J. Lavernia, D. W. He, and Y. T. Zhu, Appl. Phys. Lett. 83, 5062 (2003).

${ }^{31}$ M. Chen, E. Ma, K. J. Hemker, Y. M. Wang, and X. Cheng, Science 300, 1275 (2003).

${ }^{32}$ V. Yamakov, D. Wolf, S. R. Philipot, A. K. Mukherjee, and H. Gleiter,
Nature Mater. 1, 45 (2002).

${ }^{33}$ M. R. Barnett, Scr. Mater. 59, 696 (2008).

${ }^{34}$ G. P. Zheng, Y. M. Wang, and M. Li, Acta Mater. 53, 3893 (2005).

${ }^{35}$ D. A. Porter and K. E. Easterling, Phase Transformations in Metals and Alloys, 3rd ed. (Thornton, London, 2005).

${ }^{36}$ R. Banerjee, E. A. Sperling, G. B. Thompson, H. L. Fraser, S. Bose, and P. Ayyub, Appl. Phys. Lett. 82, 4250 (2003).

${ }^{37}$ X. D. Liu, H. Y. Zhang, K. Lu, and Z. Q. Hu, J. Phys.: Condens. Matter 6, L497 (1994).

${ }^{38}$ S. R. Phillpot, D. Wolf, and H. Gleiter, J. Appl. Phys. 78, 847 (1995).

${ }^{39}$ R. W. Siegel, in Processing of Metals and Alloys, edited by R. W. Cahn (VCH, Weinheim, 1991), p. 583.

${ }^{40}$ J. H. Rose, J. R. Smith, F. Guinea, and J. Ferrante, Phys. Rev. B 29, 2963 (1984).

${ }^{41}$ H. J. Fecht, Acta Metall. Mater. 38, 1927 (1990).

${ }^{42}$ L. Kaufman, in Phase Stability in Metals and Alloys, edited by P. S. Rudman, J. Stringer, and R. I. Jaffe (McGraw-Hill, London, 1966), p. 125. 